\title{
Secularización, regalismo y reforma eclesiástica en la España de Carlos III: un estado de la cuestión
}

\author{
Carlos M. ${ }^{a}$ Rodriguez lópez-Brea *
}

\begin{abstract}
RESUMEN
La España de Carlos III, como el resto de la Europa católica del siglo XVII, fue escenario de interesantes novedades en el panorama religioso. La esfera política luchaba desde hacia tiempo por emanciparse de las tutelas eclesiásticas, pero es sólo en el siglo xvil cuando se puede hablar con propiedad de secularización de la política. En España, el regalismo tradicional adquirió nuevos brios al mezclarse el sustrato autóctono con las ideas que provenían de Nápoles

y de Francia. Aún asi, Carlos III se mostró tan cauteloso en sus relaciones con Roma que, a finales del siglo XVIII, el clero seguía disfrutando en España de unos privilegios más amplios que en la mayor parte de las naciones católicas. La Corona, entretanto, en su empeño por consolidar el poder del Estado, se sivió para sus intereses de diversos grupos reformadores, muy heterogéneos
\end{abstract}

\section{ABSTRACT}

Charles III's Spain, like the rest of the catholic Europe in the 18th century, was the stage where interesting changes took place in the religious field. The political sphere fought a long time ago to become independent from the ecclesiastical paternity, but only in the 18th cetury was it possible to talk about secularism in politics. In Spain, the traditional regalism acquired new force when the new ideas from Naples and France mixed with a national basis. However, Charles III was so cautious in his relationship with the Roman Church that, at the end of the century, the clergy in Spain enjoyed wider privileges than in other European kingdoms.

The Crown, in the mean time, trying to reinfore the state power, used the many different reformer groups (enlightenmented catholics,

* Universidad Autónoma de Madrid. 
entre si (católicos ilustrados, jansenistas,

etc.), aunque todos ellos propugnaran cambios de la estructura eclesiástica en sentido antipontificio. jansenists...), because they all defended changes in the ecclesiastical structure in an antipontiffical way.

\section{EL REGALISMO Y LA CONSOLIDACIÓN DEL ESTADO BORBÓNICO: UNA TRAYECTORIA INCOMPLETA}

Es algo sabido que la política de los reyes Borbones trajo a España un ejercicio más absoluto y centralista de la soberanía regia. Nada ni nadie podría situarse por encima de la Corona.

Durante el Medievo, sin embargo, la primacía había sido de la Iglesia. Como heredara del universalismo del Imperio Romano, la Iglesia católica se identificaba entonces con la comunidad de hombres europeos: ser cristiano y, por eso mismo, súbdito del Papa de Roma, conferia identidad y estaba por encima de la pertenencia a cualquier reino terrenal. De las dos sociedades que Dios había instituido en el mundo, Iglesia e Imperio, los teólogos sostenían que la iglesia era la más excelente, porque su misión era conducir a los hombres hacia la felicidad eterna; dada su superioridad, la Iglesia podía y debía ejercer un control directo sobre los negocios temporales. Al amparo de esta teoría, conocida como de «las dos espadas", el clero obtuvo entonces - y perpetuó después- enormes privilegios, con un derecho y un sistema fiscal propios. Estos privilegios, desde luego, no serian concesiones de un poder temporal débil e imperfecto, sino el resultado del orden natural de las cosas, esto es, del orden querido por Dios. Si la Iglesia ejercía el papel rector de la sociedad, el Imperio no tenia otra función que coadyuvar con sus leyes a la consecución de los sagrados fines espirituales dictados por aquélla. Se podría hablar así, con toda propiedad, de una sociedad sacralizada.

Pero este esquema agustiniano comenzó a resquebrajarse a medida que los modernos estados nacionales consolidaban su posición. El nuevo Estado, personalizado en el Príncipe renacentista, sintió la necesidad de defender una jurisdicción propia independiente de la Iglesia. Pero las monarquías burocráticas del Renacimiento estaban lejos de despreciar la religión; muy por el contrario, todas ellas quisieron espiritualizarse, constituir un cuerpo místico a escala nacional. "Cada Estado - ha subrayado Claude Lefort- se convierte en un pueblo escogido que debe desarrollar una misión universal». 
Aunque la traumática ruptura con Roma de Enrique VIII de Inglaterra sea el ejemplo más conocido, convendría recordar que el muy católico Fernando de Aragón llegó a amenazar al Papa en 1508 con retirar sus reinos de la obediencia romana -incluyendo Sicilia, Nápoles y Cerdeñasi el Pontífice insistía en extender una bula de excomunión al reino de Nápoles. La amenaza nunca llegó a concretarse, pero a juicio de Koenigsberger, lo realmente sustantivo del incidente es que el Rey Católico llegara a plantearse prescindir del Papado y, por tanto, de la unidad de la Iglesia, sin ver en ello ningún perjuicio a la religión católica. En Francia, por su parte, los perennes conflictos de jurisdicción entre la Iglesia de Roma y la renovada monarquía de Francisco I sólo se aplacaron un tanto en 1516 tras la firma de un Concordato: mediante este acuerdo Francia se sometería en lo sucesivo a la autoridad espiritual -que no política- del Pontífice $y$, a cambio, la nación gala sería proclamada hija primogénita de la Iglesia ${ }^{1}$.

Pero la separación de esferas, sobre todo en los estados católicos del sur de Europa, distaba todavía de ser una realidad. No sólo porque los príncipes tuvieran pretensiones espirituales, sino también -y sobre todoporque el Papa se resistía a perder su tutela sobre los soberanos católicos. La llamada "teoría del poder indirecto", formulada entre otros por el jesuita Belarmino, ya no reconocía a la Iglesia un control directo sobre la política de los reyes pero otorgaba a los pontífices el derecho de exigir del Estado medidas coercitivas para proteger la fe católica; bien ha podido escribir Maravall que dicha teoria "fundamentaba los privilegios e inmunidades eclesiásticas, el poder [papal] de declarar nulas ciertas leyes civiles y afirmar la preeminencia del derecho canónico sobre el civil». Ahora bien, al reconocer tan sólo una superioridad directiva y "educativa" de la Iglesia sobre el Estado, el "poder indirecto" permitió a la larga distinguir con más claridad lo temporal de lo espiritual, y facilitó por ello la secularización del poder político. De igual modo el Papa, muy debilitado en su autoridad espiritual tras la Reforma luterana, necesitaba la ayuda de los orgullosos príncipes católicos, ya que sin ellos no podría difundir ni ejecutar los decretos de la reforma tridentina. De tal forma, por paradójico que parezca, el Concilio de Trento debilitó notablemente el poder de la Iglesia, porque la necesaria protección real a las disposiciones conciliares situaba al Papa y a los obispos "en una situación de dependencia del poder civil que favo-

Koenigsberger, H.G., El mundo moderno, 1500-1789. Barcelona, Ed. Crítica, 1991, pág. 49. Algunas matizaciones muy sobresalientes sobre el concepto clásico de secularización en MARDONES, J.M., "La desinstitucionalización religiosa”, Sociedad y Utopia, núm. 8 (1996), págs. 95-103. 
recia la difusión del regalismo". Y es que de la protección regia a los decretos de Trento a la directa intervención de los reyes en los negocios eclesiásticos sólo había un paso; un paso más que tentador que la mayoría de los soberanos dieron en uno u otro momento ${ }^{2}$.

El impulso definitivo en el proceso de secularización de la política hay que situarlo, sin embargo, en el llamado Siglo de las Luces. En España, sin ir más lejos, los nuevos reyes Borbones cada vez se mostraban más reacios a aceptar la autoridad papal en aquellas providencias que no fueran puramente espirituales y sacramentales (entendiendo como tales las relativas a la predicación o a la administración de sacramentos). Incidentes como la expulsión de algunos Nuncios, la imposición unilateral por parte de Carlos III del pase regio o regio exequatur sobre los documentos pontificios, o la expulsión de los jesuitas de los territorios de la Monarquía española, eran signos visibles de un nuevo orden de cosas en el que el Príncipe prevalecería sobre el Papa como fuente de legitimidad del Derecho ${ }^{3}$.

La religión, por supuesto, no desapareció de la vida pública, pero sí tendió a subordinarse a las necesidades generales de un Estado cada vez más celoso de su autonomía. Es precisamente en este deseo de someter la Iglesia al interés común -o si se prefiere, en este uso instrumental de lo religioso-, donde hay que encontrar el triunfo de la política sobre la religión. Este nuevo Estado que trataba de reafirmar su soberanía frente a las tutelas eclesiásticas, utilizó todo su aparato de propaganda para caracterizar al Príncipe como un ser virtuoso cuyo poder emanaba directamente de la Providencia. El Príncipe se convertiría asi en el auténtico vicario de Dios en el Reino y, por extensión, en la verdadera cabeza de la Iglesia católica de sus territorios. La gran paradoja, por tanto, fue que la persona del Rey tuviera que "sacralizarse" para reforzar su autoridad e independencia frente a la Iglesia. No hay nada más lejano a la realidad lo ha recordado Donézar hace bien poco-que presentar las Cortes ilustradas europeas como laicas, anticlericales y opuestas a sus Iglesias ${ }^{4}$.

Para subordinar la Iglesia al derecho común, el Monarca español disponia de algunos instrumentos muy poderosos: estaba, claro está, el re-

2 Álvarez de Morales, A., El pensamiento político y juridico de Campomanes. Madrid, INAP, 1989, págs. 32-33. Maravall, J.A., Teoría del Estado en España en el siglo xvili, Madrid, Centro de Estudios Constitucionales, 1997 (ed. original de 1944), págs. 75-86.

3 EgIDO, T. Regalismo y relaciones iglesia-Estado (siglo XVIII), en Garcia VILLOSLADA, F. (ed.), Historia de la Iglesia de España, t. IV. La Iglesia en la España de los siglos xvil y xvill. Madrid, Biblioteca de Autores Cristianos, 1979, págs. 126-129.

4 DONÉZAR, J., "La Única Contribución y los eclesiásticos", Cuadernos de Historia Moderna, núm. 21 (1998), págs. 219-263. 
galismo hispánico más tradicional, que todos respetaban, pero también, desde tiempos de Carlos III, las nuevas tesis jurisdiccionalistas que surgieron en Nápoles a comienzos del siglo XVIII ${ }^{5}$. El jurisdiccionalismo clásico, tal como lo define Jemolo, fue «un sistema de relaciones entre los dos poderes caracterizado por su distinción (en contraste con la teocracia y el cesaropapismo, sistemas de confusión y absorción recíprocos) y por su coordinación». Sus principales teóricos, no por casualidad magistrados y burócratas, buscaron en la Historia un espacio propio de la jurisdicción real con el que hacer frente a las continuas intrusiones eclesiásticas. Pero el napolitano Pietro Giannone, autor de la Istoria civile del Regno di Napoli, fue más allá; hombre de profundas convicciones católicas, Giannone, sin embargo, más que entender las relaciones entre Iglesia y Estado como la correspondencia entre dos iguales, pretendía hacer de las iglesias instituciones que vivieran en el interior del sistema jurídico del Estado. En otras palabras: el Estado era plenamente autónomo y soberano y, como tal, superior ${ }^{6}$.

Las tesis de Giannone, que tuvieron enorme resonancia en toda Europa, habrían de llegar a España a través de la doble influencia de la corte de Viena (ciudad en la que, recuerda Batllori, residieron muchos castellanos y catalano-aragoneses exiliados de España tras la Guerra de Sucesión) y de los ministros italianos de Carlos III (Giannone, de hecho, había residido en Nápoles durante el reinado italiano de este Borbón). Aquí encontraron el campo bien abonado, porque ya existía un sustrato regalista y jurisdiccionalista autóctono.

El regalismo, en palabras de Álvarez de Morales, sería un sistema jurisdiccionalista particular que "tenía por fundamento la hegemonía estatal sobre la Iglesia, acompañada, por otra parte, de una actividad de la autoridad civil dirigida a la defensa y a la protección de la Iglesia y de sus instituciones". Una defensa que, si en un principio se pudo manifestar de forma harto confusa (no quedaba claro si el Rey actuaba por su cuenta o con autorización del Papa), durante el siglo XVIII derivó en una clara subordinación de la Iglesia a los mandatos del soberano. Por decirlo muy brevemente: si el Rey defendía mejor los cánones eclesiásticos que la corrupta curia del Papa y si la autoridad del Pontífice, en su caso, se limitaba a lo espiritual, el Rey sería, con todo derecho, el "obispo exterior" de la Iglesia nacional.

\footnotetext{
El Reino de Nápoles era un territorio de larga tradición anticurialista, sin duda como reacción a las continuas intromisiones de los Estados Pontificios en sus asuntos políticos, ya que el Papa tenía derechos de soberanía feudal sobre el sur de Italia.

"Jemolo, A.C., "Giurisdizionalismo", en Enciclopedia Italiana, XVII, 1933, col. 366, cit. por Álvarez de Morales, A., op. cit, págs. 29-36. Diaz, F., Europa: de la llustración a la Revolución. Madrid, Alianza, 1994, págs. 85 y ss.
} 
En contra de lo que sostuvieron Menéndez Pelayo y sus seguidores, esta línea de pensamiento regalista (que para ellos era "extranjerizante») se puede rastrear en los muy ortodoxos escritos de los magistrados y canonistas amparados por los Habsburgo. A lo largo de los siglos XVI y XVII, revela Antonio Benlloch, numerosos tratadistas y humanistas españoles de primer orden, como Covarrubias, Cevallos o Salgado de Somoza, sin negar la autoridad primada del Papa, creyeron oportuno que el Príncipe, como protector del Concilio de Trento, interviniera más directamente en algunas cuestiones de disciplina eclesiástica (la colación de beneficios, la concesión de dispensas o la presentación de recursos de fuerza) para defender la pureza de los cánones y las leyes del Reino.

Y si intervenía el soberano, de acuerdo con estos tratadistas, era porque tenía el derecho y el deber de hacerlo en razón de su propia soberanía, y no porque estuviera autorizado por "graciosas" concesiones pontificias ?

Aun así, resultaría ridículo negar la influencia en España del galicanismo, un movimiento teológico-político que fue en Francia lo que el regalismo habría de ser en la Península. De hecho, las obras de Bossuet y Fleury, dos galicanos moderados defensores de las prerrogativas episcopales y del origen divino del poder real, eran muy conocidas en España. Tanto, que muchas de sus principales premisas (conciliarismo, nacionalismo religioso, episcopalismo, negación de la infalibilidad del Papa, independencia de la autoridad temporal respecto a la potestad espiritual), llegaron a ser lugares comunes entre las élites cultivadas del siglo XVIII.

Cosa muy distinta es que el Monarca español hiciera uso efectivo de las regalías que le reconocían sus juristas. Los Habsburgo, a pesar de la presión conjunta de funcionarios, tratadistas, y de no pocos eclesiásticos, mantuvieron una sorprendente consideración hacia las reservas romanas. No es disparatado pensar, sin embargo, que las dos partes en litigio salieran ganando con esta tolerancia: mientras el Papa salvaba la doble inmunidad

\footnotetext{
Dos visiones distintas sobre la naturaleza del regalismo borbónico son las de Alberto de la Hera, que habla de un regalismo "extranjerizante", claramente distinto al de siglos anteriores, y la de Antonio Benlloch, que prefiere ver un continuum doctrinal entre los tratadistas castellanos del siglo XVI y los regalistas borbónicos del XVIII. Es más, para Benlloch Marca, Van Espen y demás serían criaturas de los humanistas españoles del Renacimiento (DE LA HERA, A., "Notas para el estudio del regalismo español en el siglo XVIil", Anuario de Estudios Americanos, núm. 31 (1974), págs. 413-414; BENLLOCH, A., «Antecedentes doctrinales del regalismo borbónico. Juristas españoles en las lecturas de los regalistas europeos modernos", Anales de la Universidad de Alicante. Historia Moderna, núm. 4 (1984), págs. 312-317).
} 
(económica y jurisdiccional) del clero, el Rey se aseguraba un alto grado de control sobre los negocios eclesiásticos de España a través del derecho de presentación (el Patronato de Indias, sin ir más lejos, fue reconocido por el Papa a comienzos del siglo XVI) y conseguía dinero de la Iglesia mediante el sistema impositivo de las Tres Gracias (excusado, subsidio y cruzada), las annatas, las tercias reales y el régimen de pensiones. Se ha llegado a hablar, entre otros Donézar, de un duradero pacto «no escrito" entre Monarquía española e Iglesia romana, que entretejían asi sus intereses comunes.

Durante el siglo XVIII este pacto comenzó a dar muestras de agotamiento, si bien la Monarquía borbónica muy rara vez se dejó llevar por el regalismo de los más radicales, y prefirió las transformaciones lentas, del día a día. Esta lentitud, sin embargo, era más estratégica que sentida, porque en ausencia aún de un poder político fuerte y consolidado, no parecía prudente que la Monarquía atacase los privilegios del clero de forma directa. De tal modo, a pesar de la pluralidad y riqueza del pensamiento regalista español, los reyes Borbones y muy singularmente Felipe $V$ y Fernando VI, sólo prestaron verdadero interés al llamado regalismo "beneficial». De hecho el Concordato de 1753, que autorizaba al Rey a presentar la casi totalidad de obispos, canónigos y beneficiados de España y América, permitió a la Monarquía alcanzar el mayor grado posible de autonomía beneficial: el Patronato Universal. Una conquista que, si bien se presentó como un gran éxito de la diplomacia española, sólo suponía adecuarse al nivel de competencias alcanzado por otras monarquías católicas - particularmente la francesa- dos siglos antes.

Desde esta lógica gradualista parecía razonable que, una vez agotada la vía beneficial, Carlos III y sus ministros quisieran reforzar la autoridad del Monarca en otras cuotas de jurisdicción menos exploradas por sus antecesores. Es lo que Egido ha llamado "ampliación del campo de las regalías". Se trataría de establecer, pero muy a largo plazo, un nuevo marco de relaciones con la Iglesia en el que no cupieran tantas legislaciones especiales, privilegios tributarios o riquezas amortizadas.

En primer término, el Monarca pretendió reclamar una mayor "cuota" de orden público, sin la que no se puede hablar propiamente de Estado: fue Max Weber quien teorizó, hace ya muchas décadas, que el Estado como tal debe ejercer el monopolio de la violencia. "Si la autoridad eclesiástica seguía encarcelando, juzgando, condenando, incautando bienes e imponiendo impuestos según sus propios criterios - ha escrito SánchezBlanco-, el Estado no era gobernable y el Monarca que, no en cuanto individuo sino en cuanto función pública personificaba el orden civil, tenía un 
interés institucional en impedir que determinadas atribuciones quedaran fuera del Estado» ${ }^{8}$.

$Y$ aunque los resultados de esta politica no siempre fueran los apetecidos, no se pueden soslayar algunas novedades. La más sobresaliente, desde luego, la tortuosa imposición del exequatur -instituido en 1762, retirado al año siguiente y recuperado en 1768 ya de forma permanente-. entendido como una fórmula defensiva contra un posible ataque a la soberanía regia. Pero tampoco podrían obviarse la expulsión de los jesuitas y la posterior ocupación de sus temporalidades — una medida tendente a garantizar la «tranquilidad interior» del Reino frente a las aparentes, y nunca probadas, maquinaciones de estos religiosos-, el progresivo control estatal de las Universidades, hasta entonces cotos cerrados de la Iglesia, la generalización de los recursos de fuerza - ya comunes en Francia desde finales del siglo $x \mathrm{~V}$ - que permitian reclamar ante un tribunal civil la posible sentencia abusiva de otro eclesiástico o la prohibición de que la Iglesia castigara las faltas espirituales con penas corporales o multas. Igualmente se legisló para que los jueces eclesiásticos no pudieran prender a personas civiles o secuestrar sus bienes sin el auxilio del brazo secular pues en estos casos, señalaba uno de los reales decretos, la imposición de penas en el “foro externo y criminal» debía reservarse únicamente a los jueces civiles. Da la impresión, sin embargo, de que Carlos III no trató tanto de negar el fuero particular de los eclesiásticos, cuanto de «tutelarlo»y limitarlo en su propio beneficio.

Ya en el terreno ideológico se decretó que fuera el poder real quien, al margen de la Inquisición, concediera o negara el permiso para la impresión y circulación de libros, reservándose tan sólo a la Iglesia «calificar en modo y forma las doctrinas"; medida novedosa aquí pero que los ministros Kaunitz y Pombal ya habian aplicado con éxito en sus respectivos países, Austria y Portugal. La capacidad censora y represora de la Inquisición quedaría así limitada a materias estrictamente dogmáticas y morales, si bien fue práctica común que la censura civil, con la doble excusa de defender las regalías y de promover las "buenas costumbres" del Reino, actuara con mayor saña que la eclesiástica en la persecución de libros "peligrosos" (éste sería un buen ejemplo del "uso político" de la religión al que antes aludiamos). La Inquisición, muy debilitada con estas medidas, recibió un nuevo golpe en 1770 , cuando una Real Cédula previno que este tribunal mixto, civil y eclesiástico a un mismo tiempo, entendiera en lo sucesivo

- Sánchez-Blanco Parcdy, F., Europa y el pensamiento español del siglo xvili. Madrid, Alianza, 1991, págs. 293 y 338. 
"Solamente de los delitos de herejía y apostasía" (y no, por ejemplo, de los de impiedad), dos faltas para cuya persecución este Tribunal había sido originariamente instituido en tiempos de los Reyes Católicos ${ }^{9}$.

Todas ellas fueron medidas de una indudable raigambre modernizadora, pero la verdad es que, al margen de la expulsión de los jesuitas de los territorios de la Monarquía española (un decreto que, por cierto, el papa Clemente XIV refrendó pocos años después), de la imposición del exequatur (común, como se ha visto, en la mayor parte de la Europa católica) y de ciertos incidentes aislados con la Inquisición o con algún que otro obispo ultramontano, la Monarquía borbónica actuó con la mayor prudencia, buscando el pacto con Roma en la medida de lo posible. Tanta moderación, mezclada con algunas muestras aisladas de autoritarismo para satisfacer las demandas de los sectores más radicales, era resultado de una política habilidosa que, sin embargo, obligaba a grandes renuncias.

De este modo, aunque hubo cambios indiscutibles en el marco general de relaciones entre Iglesia y Estado (no hay más que leer los dos primeros tomos de la Novísima Recopilación para comprobarlo), Carlos III resultó ser un rey muy cauteloso en sus relaciones con la Iglesia. La emperatriz de Austria, María Teresa, y su hijo José II, contemporáneos suyos, crearon un Departamento de Asuntos Eclesiásticos que durante el reinado de José liegó a emitir seis mil ordenanzas religiosas. Aunque muchas de ellas eran disposiciones absurdas que reglamentaban hasta la liturgia de los templos, otras tuvieron un hondo significado político: por ejemplo, la abolición en los territorios del Imperio del derecho de asilo, la supresión de setecientos conventos y monasterios, el sometimiento de los regulares a los obispos, la regulación de fiestas y matrimonios con criterios puramente civiles, la prohibición de la censura eclesiástica e incluso, la tolerancia de los cultos. Todo ello, escribió el llamado "Rey Sacristán", lo disponía atendiendo únicamente a la voz de la conciencia, "que me dice lo que como legislador y protector de la religión me conviene hacer y dejar de hacer, y esta voz, con la ayuda de la gracia divina y con el carácter honesto y ecuánime que creo tener, no puede jamás inducirme al error". El episcopado austriaco, tan regalista como su Emperador, aceptó estas reformas de buen grado. Un poco más al sur, en el Gran Ducado de Toscana, el príncipe Pedro Leopoldo - hermano de José- tampoco se quedó atrás. El Príncipe, con la inestimable ayuda de su fiel ministro Giulio Rucellai, sin

\footnotetext{
9 Novisima Recopilación de las Leyes de España, lib. I, tít. VIII, ley X; lib. II, tít. II, ley XXIV y tít. III, ley IX; lib. VIII, tít. V, leyes III-IV y tít. XVIII, leyes III-VII y IX; lib. VIII, tit. XVIII, ley III; lib. XII, tit. XXVIII, ley X.
} 
recurrir en ningún momento a la autoridad del Papa, abolió en su minúsculo territorio los tribunales de Inquisición y de Nunciatura, prohibió la adquisición de tierras por manos muertas, suprimió algunos monasterios y conventos, dispuso que los juicios penales del foro eclesiástico debian seguir el voto expresado por un ministro real y la subsiguiente aprobación soberana, y reguló el número necesario de sacerdotes para la atención espiritual de sus súbditos. Francia era punto y aparte, porque el clero privilegiado lo era, como la nobleza, por plena voluntad del Rey y no porque lo dijeran los cánones ${ }^{10}$.

El regalismo, en suma, no alcanzó aquí las cotas de un Leopoldo, de un José II y ni tan siquiera las de un Carlos VII de Nápoles, antiguo fustigador de las inmunidades del clero, transmutado en España -especialmente tras el éxito de los motines de 1766- en un mucho más precavido Carlos III.

No es de extrañar, que, a pesar de los logros del regalismo oficial, los eclesiásticos españoles disfrutaran en 1800 de un fuero más extenso que en ninguna otra parte. $O$ que los tribunales diocesanos pudieran procesar y castigar a sus súbditos eclesiásticos con penas temporales de las que tan sólo, atendiendo a la "lenidad y mansedumbre" que se suponía propia del estamento clerical, estaba excluida la pena de muerte. Esta jurisdicción, apunta Candau Chacón, se extendía igualmente sobre los laicos bautizados en la fe católica, "de forma que el quebrantamiento de las leyes eclesiásticas les ocasionaba, asimismo, la apertura de proceso judicial»" ${ }^{11}$. Sirva como consuelo decir que, al menos desde tiempos de Carlos III, los jueces eclesiásticos tenían prohibido prender a civiles o secuestrar sus bienes sin el auxilio de la justicia civil. Pero el derecho de asilo, por contra, aunque estuviera limitado por sucesivos decretos, aún seguía siendo una realidad en 1800 .

En el terreno económico, tras el sonoro fracaso del fiscal Melchor de Macanaz, promotor de políticas desamortizadoras, el Concordato de 1753 hizo posible que la Monarquía utilizase en su beneficio las rentas de sedes y beneficios vacantes. Sin embargo, no se avanzó al mismo ritmo en la regulación de la propiedad eclesiástica del Reino. Ciertamente se atacó con saña la adquisición de bienes raíces por las manos muertas (Campomanes teorizó en su Tratado de la regalía de amortización que las manos muertas no podian adquirir tierras sin la autorización del rey), pero los verdaderos

10 Diaz, F., op. cit., págs. 360-361 y 502-504.

11 Candau Chacon, M.L., Los delitos y las faltas en el mundo eclesiástico sevillano del siglo xviI. Sevilla, Diputación Provincial, 1993, pág. 25. 
resultados de esta política fueron muy modestos. Ni tan siquiera se pudo conseguir que el clero pagase regularmente la contribución que el Concordato de 1737 había impuesto sobre las tierras que la Iglesia adquiriese en el futuro (los eclesiásticos no sólo hicieron caso omiso a lo dispuesto en dicho Concordato sino también a las sucesivas leyes de 1745, 1760 y 1793); ni que decir tiene que las tierras "viejas", a pesar de las tentativas impulsadas por ministros como el marqués de la Ensenada o Cabarrús, no pagaban ninguna contribución regular. Otra cosa es que la Iglesia, con el consentimiento de los papas, no mitigara generosamente las necesidades de la Monarquía con donativos y subsidios voluntarios; pero donar no era lo mismo que contribuir, ya que esto segundo exigía un estrecho control estatal de la riqueza de los contribuyentes y una cierta regularidad en los pagos, lo que no era el caso. Con subsidios y donativos, en cambio, la inmunidad eclesiástica quedaba a salvo. El diezmo, por último, un impuesto "privado" que obligaba a todos los productores españoles, siguió siendo el sustento económico de la Iglesia, por mucho que la intervención del poder civil en su cobro y en su recaudación fuera cada vez mayor a lo largo del reinado de Carlos III ${ }^{12}$

Dicho de otro modo: el clero español mantenía a comienzos del siglo $X I X$ sus tres inmunidades tradicionales, la personal, la real y la local. $Y$ no sólo eso. Ante la desidia del Estado español, la Iglesia también creía poseer derechos inalterables en la instrucción pública y en la atención a los enfermos. Singularmente escandaloso era el negocio de las dispensas (sobre todo las matrimoniales, que sólo podía conceder el Pontífice tras mediar un informe del obispo correspondiente), por cuyo pago España enviaba todos los años importantes sumas de dinero que muchas veces se quedaban en manos de agentes y de intermediarios; si este comercio ya de por sí era reprobable, aún resultaba más inmoral que la Iglesia hubiese creado un aparato administrativo que se enriquecia dispensando del cumplimiento de sus propias leyes. EI Nuncio Apostólico, por su parte, que en Francia, Austria, Nápoles o Baviera era sólo un embajador político sin funciones judiciales, aquí actuaba como presidente del Tribunal de la Rota española - creado en 1771-, de tal forma que un extranjero, aunque auxiliado por auditores patrios, tenía la más alta jurisdicción sobre todos los eclesiásticos españoles; pocas cosas podían resultar más repelentes para la mentalidad regalista y nacionalista de los ministros borbónicos.

A pesar de las cautelas de Carlos III, los burócratas que le rodeaban eran muy conscientes de los males de la Monarquía. La Instrucción Reservada

12 Nov. Rec., lib. I, tít. IV y tít. V, leyes XVI-XVII. 
que Carlos III dictó a la Junta de Estado en 1787, un año antes de morir aunque la autoría real del texto se atribuye generalmente al conde de Floridablanca-, era de hecho un catálogo de lo mucho que aún faltaba por hacer en materia eclesiástica. La Instrucción era un amplio abanico de actuaciones del que tan sólo se excluirían los negocios espirituales, reservados al Papa ("por ningún caso ni accidente dejen de obedecerse y venerarse las resoluciones tomadas en forma canónica por el Santo Padre»), y que propugnaba, entre otras cosas, nacionalizar las órdenes regulares, limitar la amortización de tierras, combatir las supersticiones populares o controlar políticamente la Inquisición. Pero, temeroso de que un hipotético concilio nacional pudiera cuestionar la autoridad del Rey sobre la Iglesia, Floridablanca aconsejaba abordar este elenco de asuntos por vía concordataria; no sólo, como se decía, para "conservar la paz y armonía con los Sumos Pontífices" sino también para asegurarse la absoluta sumisión del clero nacional a los decretos reales ${ }^{13}$.

Tantas décadas de regalismo, y la Monarquía católica ni siquiera había sido capaz de controlar completamente el clero español. Sería Godoy, hombre inteligente e ilustrado, quien supiera aprovecharse de la debilidad política y moral del Papado para avanzar un poco más en el campo de las regalías «no beneficiales». No siempre lo logró, pero los tiempos del Príncipe de la Paz ya fueron otros.

\section{2. ¿JANSENISTAS, REGALISTAS O REFORMISTAS? ALGUNOS APUNTES SOBRE LA REFORMA ECLESIÁSTICA EN LA ESPAÑA DE LA ILUSTRACIÓN}

Este recorrido por la política eclesiástica del siglo XVIII, necesariamente breve, quedaría muy incompleto si no se mencionaran los movimientos de renovación que pulularon en la Iglesia durante la segunda mitad de la centuria. Porque el regalismo, ideología plural bajo cuyo manto se refugiaron todos los intelectuales de entonces (son contados quienes presumieron de antirregalistas), necesitaba amplios apoyos eclesiásticos para la consecución de sus fines unificadores.

Si hemos de hacer caso al ingente volumen de lo que han escrito historiadores y teólogos, la más sobresaliente de estas corrientes renovadoras

13 Gobierno del señor rey Carlos III o Instrucción reservada que la Junta de Estado, creada formalmente por mi decreto de este dia ( 8 de julio de 1787), deberá observar en todos los puntos y ramos encargados a su conocimiento y examen, en MURIEL, A., Historia de Carlos IV, en SECO Serrano, C. (ed.), Biblioteca de Autores Españoles (115). Madrid, Atlas, 1959, págs. 303-311. 
durante el siglo XVIII sería el denominado, según los diferentes autores, jansenismo, para-jansenismo, "tercer partido", jansenismo difuso, criptojansenismo, post-jansenismo, jansenismo tardío, jansenismo histórico, filojansenismo o neojansenismo. Éste - por llamarlo de algún modojansenismo dieciochesco fue un movimiento plenamente ortodoxo, cuya verdadera importancia, sin embargo, se ha exagerado de forma abusiva. En aquellas décadas, el jansenismo apenas mantenía una difusa relación con el pensamiento de Cornelio Jansenio, teólogo holandés del siglo XVII que llevó hasta sus últimas consecuencias la doctrina de la gracia de San Agustín - Jansenio, como antes Lutero, daba más importancia a la acción divina que al libre albedrio-, y cuyas tesis habían sido condenadas por heréticas en las bulas Cum occasione (1653) y Unigenitus (1713).

Este movimiento teológico, sin embargo, fue poco a poco derivando en una actitud religiosa que propugnaba la vía del amor de Dios y una moral más rigorista y, lo que nos interesa aún más, en una corriente defensora de un nuevo marco jurisdiccional para la Iglesia. Poco quedaba, pues, de los principios teológicos de Jansenio, como no fuera una férrea y ortodoxa defensa de la doctrina de la gracia de San Agustín. Así, un jansenista del XVIII querrá, entre otras cosas, un clero limitado a su misión espiritual, sin riquezas, una mayor autonomía de los obispos respecto del Papa - se considera que el obispo lo es por derecho divino, y no por delegación del Pontífice-, la subordinación de los regulares a la autoridad del obispo, el retorno a una idilica disciplina "antigua" o el final del vergonzoso negocio de las dispensas apostólicas ${ }^{14}$. Al no reconocer en la Iglesia ninguna autoridad "exterior" para exigir la sujeción a sus decretos más allá de los límites de la persuasión, el jansenista dieciochesco dejaba en manos del Estado todo el aparato coactivo, algo que, lógicamente, sólo podía ser visto con simpatía por los regalistas. Además, al criticar ciertas actitudes del clero, sobre todo la posesión de riquezas, los jansenistas - quizá sin pretenderlo- minaron la teórica fortaleza del estamento eclesiástico, haciendo con ello más sencillo el triunfo de los distintos programas regalistas y desamortizadores ${ }^{15}$.

\footnotetext{
14 Según Appolis, el jansenismo español presentaba unos rasgos muy definidos: "oposición doctrinal al molinismo, desprecio de la moral laxa, odio a los jesuitas, tendencia regalista, catolicismo ilustrado y episcopalismo anticurial" (APPOLIS, E., Les jansenistes espagnoles. Bourdeaux, Sobodi, 1966).

15 Fraile Miguélez, M., Jansenismo y regalismo en España (datos para la Historia). Cartas al Sr. Menéndez Pelayo. Valladolid, Imprenta de don Luis N. Gaviria, 1895. TomSICH, M.G., El jansenismo en España. Estudio sobre las ideas religiosas en la segunda mitad del siglo xvill. Madrid, Siglo XXI, 1972. Demerson, P., Maria Francisca de Sales Portocarrero, condesa de Montijo. Una figura de la llustración. Madrid, Editora Nacional, 1975. VILLAPADIERNA, I., «El jansenismo español y
} 
Ahora bien, en la defensa de este programa participaron con diferente grado de ardor otros muchos reformistas, eclesiásticos o no (por ejemplo, el Lorenzana anterior a 1790 o el ecléctico jurista Mayans), más influidos por el humanismo español del siglo XVI que por el fatalismo propio del jansenista. Sería más apropiado, pues, no hablar tanto de jansenismo como de un heterogéneo movimiento reformista, con manifestaciones más o menos radicales, que impregnó a buena parte del clero español de la segunda mitad del siglo XVIII. Por encima de sus discrepancias, muchísimas, todos estos reformistas coincidían en algo fundamental: tenía que ser la Monarquía, y no la Iglesia, la que procediera a reformar la estructura eclesiástica sirviéndose de las regalías. Fueron muy pocos quienes preferían que el clero se reformase a sí mismo, sin injerencias del Estado.

Aunque hoy en día, por influjo de los trabajos de Antonio Mestre, se haya incidido más en las raíces hispanas del reformismo (humanistas de raigambre erasmista como fray Luis de León, Santa Teresa o los idealizados concilios visigodos) ${ }^{16}$, no parece justo ignorar la enorme importancia que tuvieron las influencias foráneas: el amplio abanico conformado por galicanos y jansenistas franceses (Bossuet, Fleury, Aleixandre), canonistas críticos de la escuela de Utrecht (Van Espen, Opsträet), católicos ilustrados (Muratori), pistoyanos (Ricci o Tamburini), regalistas (Cestari) y episcopalistas radicales (Febronio y Pereyra) ${ }^{17}$.

Semejante mezcla explicaria las dificultades que han tenido los historiadores a la hora de definir el reformismo del que hablamos. Marcelin Défourneaux, por ejemplo, llegó a identificar dos realidades tan contradictorias como jansenismo y movimiento ilustrado (es célebre su definición de jansenismo como "la modalidad religiosa de la llustración"), simplemente porque ambos movimientos defendian un programa eclesiástico muy similar (episcopalismo, Iglesia más pobre, lucha contra la superstición, estudio de la Biblia en lengua vulgar, etc.). En su caso, nos parecería más correcto hablar de una estrecha sintonia entre jansenismo y pre-llustración

las Cortes de Cádiz", Nuove ricerche storiche sul Giansenismo. Analecta Gregoriana. Series Historiae Ecclesiasticae, núm. 71 (1954). SAugNiEuX, J., Les Jansénistes et le renouveau de la prédication dans l'Espagne de la seconde moitié du XVIIle siécle. Lyon, 1976. MESTRE, A., llustración y reforma de la Iglesia. Pensamiento político-religioso de don Gregorio Mayans y Siscar (16991781), Valencia, Ayuntamiento de Oliva, 1968. Egrdo, T., La religiosidad de los ilustrados, en La época de la llustración. Historia de España (fundada por Menéndez Pidal y dirigida por José M. ${ }^{a}$ Jover), t. XXX, v. I, Madrid, Espasa, 1987, págs. 398-435.

16 Mestre, A., "La actitud religiosa de los católicos ilustrados", en GuimerÁ, A. (ed.), El reformismo borbónico. Una visión interdisciplinar. Madrid, Alianza, 1996, págs. 151-153.

17 Rosa, M., "El movimiento reformador que culmina en el Sinodo de Pistoia", Concilium. Revista Internacional de Teologia, núm. 17 (1966). CORTS I BLAY, R. L'arquebisbe Fèlix Amat (1750-1824) i lúltima llustració espanyola. Barcelona, Herder, 1992, págs. 3-9. 
(Batllori ha advertido que, en rigor, sólo se podría llamar "católica» a la llustración más temprana) puesto que el movimiento ilustrado fue paulatinamente evolucionando hacia un deísmo que emancipaba al hombre de las últimas tutelas de la Iglesia católica.

Quizá por ello, Sánchez-Blanco más que de "catolicismo ilustrado" - término tan querido por Mestre, Egido y la mayor parte de los estudiosos actuales - haya preferido llamar eclécticos a estos católicos reformistas. Según Sánchez, los eclécticos pre-ilustrados bien simbolizados por Mayans, "por temor a la posible heterodoxia pusieron la obediencia a la autoridad doctrinal y el respeto a problemáticas tradicionales piadosas por encima de la evidencia empírica y de la crítica racional»; unos principios que mal podian casar con el rumbo emancipador que habia tomado la llustración europea en las décadas finales del Siglo de las Luces. En este sentido, los ilustrados españoles más dignos de este nombre, muy pocos, defendieron una religión natural al margen del providencialismo y de la revelación. Se trataría de deístas que, aunque se apartaron del magisterio eclesiástico, rarisima vez se "descristianizaron". Se podría concluir, por ello, que los llamados católicos ilustrados españoles no lo fueron tanto porque mantuvieron actitudes pre-ilustradas en plena llustración ${ }^{18}$.

Admitida la objeción conceptual de Sánchez-Blanco, ¿podríamos distinguir al católico ilustrado del jansenista? No es tarea sencilla. Quizá un rasgo que defina exclusivamente al jansenista sea ese pesimismo moral relacionado con la idea agustiniana (asumida también por los tomistas puros tan a la moda en el siglo XVIII) de que el hombre no podía alcanzar la salvación sin la constante ayuda de la gracia divina. Los católicos ilustrados, por contra, son optimistas y defienden la libertad humana. No parecen tan interesados como los jansenistas en las luchas de escuela o en la inmediata resolución de ciertos problemas canónicos en sentido antipontificio - confirmación de obispos, concesión de dispensas...- pero, en cambio, frente a la concepción eclesiológica más «clerical» de los jansenistas, los ilustrados propugnaron una mayor presencia de los laicos en la vida de

18 DéFourneauX, M., "Jansénisme et régalisme dans l'Espagne du XVIII siècle", Caravelle, núm. 11 (1968). SANCHEZ-Blanco, F., La llustración en España. Madrid, Akal, 1997, págs. $24-27$ y 33-35. BatLloRI, M., "L'lluminismo e la Chiesa", en Problemi della Chiesa nei secoli XVII-XVIII. Atti del $V$ Convegno di Aggiornamiento (Bologna, 3-7 settembre 1979). Napoli, 1982, págs. 191-202. MEstRE, A., La llustración católica en España, en Liberalisme chrètien et catholicisme libéral en Espagne. France et Italie dans la première moitié du XIXe siècle. Aix-en-Provence, Publications de I'Université, 1989, págs. 3-20. ELORzA, A. "Cristianismo ilustrado y reforma política en fray Miguel de Santander", Cuadernos Iberoamericanos, núm. 214 (1967), págs. 73-107. 
la Iglesia. $Y$ he aquí la última y principal diferencia: si el jansenismo fue un movimiento de eclesiásticos, el reformismo católico implicó a los más diversos sectores de la sociedad española, siendo los seglares, incluso, sus principales impulsores ${ }^{19}$.

Tampoco se puede identificar, sin mayores argumentos, jansenismo con regalismo. Los jansenistas, en teoría más partidarios de una reforma dirigida por los obispos, se hicieron regalistas al comprobar que la Monarquía era el único instrumento que podría hacer triunfar la reforma eclesiástica que querían. Que los regalistas no eran jansenistas resulta todavía más evidente. Si durante el reinado de Fernando VI la Monarquia había sido hostil al jansenismo, protegiendo incluso a sus rivales jesuitas, en tiempos de Carlos III se produjo una evidente conjunción de regalistas y de jansenistas en la defensa de las reformas antes apuntadas. Esta circunstancial identificación entre jansenismo y regalismo, sin embargo, duró bien poco. Desde aproximadamente 1790 Godoy, aunque regalista como los políticos de Carlos 111, prefirió negociar las reformas directamente con una debilitada Roma y, en consecuencia, marginó -y en ocasiones persiguió- a los jansenistas.

Además, jansenistas en sí parece que hubo pocos por mucho que un joven Jovellanos hubiera escrito aquello de que en Salamanca «toda la juventud es port-royalista de la secta pistoyense". Es legítimo pensar, por el contrario, que estas espontáneas declaraciones de jansenismo no fueron más que una moda, una pose superficial de rebeldía juvenil. Siendo rigurosos, pues, podriamos considerar auténticamente jansenistas a un Armanyá, a un Climent, a un Bocanegra, a un Blasco, a un Espiga, a un Villanueva y a algunos dominicos que interpretaban con fanatismo las doctrinas de Santo Tomás, pero no a muchos otros. Tanto es asi que algunos estudiosos, como el padre Miguélez, o mucho más recientemente Egido, han negado la existencia del jansenismo español. «El tan manoseado jansenismo español -escribió Miguélez hace ya más de un siglo- se reducía a poner en tela de juicio la autoridad de los Papas cuando no le era favorable, a impedir el cumplimiento de sus apremiantes órdenes, bajo el ridiculo pretexto de que se informara mejor, y a tratarles como de potencia a potencia siempre que se interponian, por la parte de acá, el interés propio y un falso celo autoritario rayano al orgullo". No parece sino que la España repleta de heterodoxos y jansenistas fue fruto de la imaginación de los intelectuales más conservadores, bien simbolizados por don Marcelino Menéndez Pelayo.

19 Mestre, A., "La actitud religiosa de los católicos...”, págs. 158-163. 
Catolicismo ilustrado, regalismo y jansenismo no son, por tanto, una misma cosa. Ocurre, sin embargo, que los tres movimientos compartieron ideas y proyectos que terminaron por ser un lugar común entre todos aquellos que defendieran una reforma eclesiástica en sentido antipontificio. Ante esta indefinición fue la Monarquía -el regalismo oficial en definitiva- quien controló y dirigió las corrientes de espiritualidad y el poder eclesiástico. Y es que como bien intuyó Antonio Mestre, "lo que importaba era el control de la Iglesia Nacional; las demás consecuencias son secundarias" 20 .

Lo que hubo, más allá de otras absurdas disquisiones, fue una suerte de reformismo difuso, "contaminado" por numerosas influencias, pero con un sustrato común. Un movimiento reformista que, independientemente de cómo se defina, fue poco coherente, sustentado por individuos y no por grupos organizados. A fin de cuentas, tratar de averiguar-como a veces se ha hecho- si tal o cual personaje fue jansenista, regalista o ilustrado, o las tres cosas a la vez, puede resultar un ejercicio ridículo porque todos ellos, reformistas, fueron hijos de un tiempo confuso e inseguro, de una época de cambios en la que, casi a diario, bullian nuevas ideas y proyectos.

20 Mestre, A., “La actitud religiosa de los católicos...", op. cit., pág. 160. 